\title{
Winnipeg's Aspirational Port and the Future of Arctic Shipping (The Geo-Cultural Version)
}

\author{
Stephanie C. Kane
}

Ethnographers usually study ice/water and culture in contemporary and historical timespaces. They tend to start somewhere between present tense and time immemorial of Indigenous peoples. This corresponds to a tiny sliver of timespace in geological terms. But if ethnographers and humanities scholars more generally want to understand humans as geological actors with powers and ethical responsibilities to influence planetary ice/water futures, then we must invent ways to stretch culture into geo-culture. ${ }^{1}$ Most human actions causing break-up and melting of Arctic sea ice, among other effects and drivers of climate change, have occurred within the last one hundred years or so. ${ }^{2}$ However, I believe that ethnographers might think about humans as we think about glaciers-place-based and place-transiting collective, embodied agents who act in processes that extend back into the last ice age.

Representations of water (and water bodies) generally tend to be dynamic but inert, or at least always imagined as bound by Nature's laws to act accordingly. ${ }^{3}$ Ethnographic waters are universally required and manipulated, ritualized, rerouted, and polluted by people whose actions focus whatever dreams and dramas are at stake. ${ }^{4}$ But I wonder, how might the drama of a melting Arctic Ocean be plotted as one in which agencies are shared more equally between humans and water? Or, better still, a drama in which both humans and ice/water have agential powers that form and act materially and culturally on the stages of Earth's amphibious crust? ${ }^{5}$

In this chapter, I experiment with a geo-cultural approach that focuses on collective actors in global shipping. Global shippers have contributed unintentionally and indirectly, but nevertheless certainly, to Arctic sea ice loss. As they now approach widening passages through retreating sea ice as opportunities to facilitate more efficient global trade, in the process, their fossil-fuel-burning, ice-breaking 
ships may accelerate sea ice loss. The city of Winnipeg in Manitoba, Canada, with its oddly placed aspirational port and glacial destiny, is the focal point for this geocultural experiment.

Diverse human collectives often come together to reconfigure and integrate various water bodies, altering their direction of flows and forging new interconnections among them. The engineered aquatic thing that results demands continuing attention from people who would attempt to borrow its essential power. In Impossible Engineering, her history of a seventeenth-century French interoceanic canal, the Canal du Midi, Chandra Mukerji (2009) opens up an infrastructural path towards narrating water's agency. Mukerji writes (204):

The waterway became both an unquestionable fact of local life like a mountain or a wild river, laying down the conditions of possibility for all those living near it, and the opposite: a product of collective action and an ongoing raison dêtre for social coordination.

A fact of life and a product of collective coordination: these are existential features of a social relationship in which water lends its "logistical power" to humans and in so doing organizes (and sometimes thwarts) their capabilities and mobilities. Mukerji $(2009,214)$ distinguishes logistical power conferring dominion over things (such as water) from strategic power conferring dominion over people. Logistics, "or the mobilization of natural forces for collective purpose," brings "different types of power to social life." The concept of logistical power frees this author from the claustrophobic struggle between interest groups to explore possibilities for a political ecology of water that takes water's agency, or waters' agencies, seriously.

What I take away from Mukerji's history is the idea that water's power, as people attempt to move it this way and that through varied configurations of rock and soil, has to work through an appreciation of its changeable, interactive nature. Human intention emerges in place and in process. People have to feel their way along as they navigate the conditions of possibility that water bodies allow. To achieve this sense of the entwined agencies of humans and water in geological timespaces, I find it useful to broaden our view of human agency, to actively acknowledge and explore unintended spheres of even our most intentional actions. ${ }^{6}$

In the spheres of unintended effects, and affects, I propose that agencies of water and humans interact more equitably. Once one moves human intention into the background, shocking stories of climate change, such as melting of the Arctic Ocean as existential hazard and capitalist boon, can be told otherwise, and perhaps better questions can be asked.

Human collectivities, some more than others, have caused climate changes that have dramatically altered human-water relationships. A significant cultural fact attends this scientific fact: humans have unintentionally caused climate change. 
Scientists have identified intentional actions that drive climate change-fossil fuel use the most prominent cause and Arctic sea ice loss a prominent effect. Humanities scholars, however, may well be better positioned to explore significant unintentional drivers of anthropogenic climate change. They can do so by ceding the focus on intentional human agency in every narrative, sharing agency with water.

Integrating the scientific fact of climate change into culture is difficult. Toward this end, I do believe that (re)writing human-water interactions within the sphere of unintentional agencies could dampen anthropocentric bias and lead to circulation of other kinds of climate change narratives. I do this analytically here by carrying port city ethnography into geoscience research that illuminates how ice/ water moves in and across Earth's crust. When I poach geoscience narratives that precede human encounter, yet a second door out of the human-struggle-interest box opens. Through it, I try to find my way into a humbler, yet scientifically allied sense of the real that stretches the future back before time immemorial.

This chapter takes up this book's aquatic humanities theme by tackling a sphere of unintentional agencies relating to maritime engineering, ice/water geology, and the city. The chapter has three main sections and a conclusion. The first two sections shift analysis of human-water relationships in new directions using two experimental maneuvers. The third brings it all together in Winnipeg. First, I articulate a double human-water maneuver that shifts conventional water discourse. On the human side of this relationship, I shift away from particulars of our intraspecies collaborations and confrontations and toward meso-scale collective actions that create port cities and monumental water engineering projects. ${ }^{7}$ And on the water side of the relationship, I shift away from abstract flows and cycles and toward meso- and macro-scale water bodies, such as river basins, lakes, and oceans. I flesh out this double human-water maneuver by examining Winnipeg's aspirational port through a historical lens of port cities, interoceanic canals, and other key technological revolutions in the global transport industry.

Second, I attempt to recast the meaning of the term anthropogenic so as to downplay the significance of human intention in the understanding of climate change. To accomplish this, I mine the published work of geoscientists, who thus become some of my most important key informants. Their work allows me to expand timespaces of human encounter into the geological scale, expanding narrative from the sliver of human presence into the Quaternary Period. In classical geology, the Quaternary begins in the ice age of the Pleistocene Epoch, continues into the current Interglacial, the Holocene Epoch. The Holocene climate melts ice age glaciers to create the major North American water bodies that govern contemporary human activity in and beyond the continent. This second maneuver-qualifying our sense of the anthropogenic by highlighting the power of ice/water-synchronizes our sense of the timespaces of human unintentional actions and effects with the timespaces of water's unintentional actions and effects leading up to the Anthropocene and its various near-end-Holocene variants. In 
other words, I mine geoscience for visual and narrative data that animate ice/water dramas before and after humans emerged and evolved. By resignifying the role of the unintentional in the anthropogenic, I cede agency to ice/water.

In the third section, narrations of port city history and ice age geoscience converge in the peculiar matter of Winnipeg's aspirational port. CentrePort is peculiar in two senses: for one, it is nowhere near a seacoast (hence its geographically appropriate name). And too, as mostly assigned space and infrastructure waiting to catch up to an idea, CentrePort remains culturally and geographically marginal to its city. ${ }^{8}$ Conceptually, however, the anticipation upon which it builds enters into geo-cultural analysis in compelling ways.

The inspiration for this particular piece of my ethnographic puzzle comes from a curious cartographic coincidence. In analysis of materials collected in my study, visual data from CentrePort public relations crossed paths with that of geoscience. The odd intersection winds up crystallizing my argument that water's agency can best be realized at the scale of the melting Arctic Ocean (which is also the planetary scale of climate change and global shipping). That the coincidence appeared at all, I suppose, is evidence in favor of a free-wheeling impulse to roam across interdisciplinary spaces among humanities scholars. Humanities-style roaming opens up new pathways for systematic inquiry, lending imaginative power to scientific knowledge. This is not about illustrating received scientific knowledge. It is about thinking science otherwise.

In analysis to follow, I treat the archive of technical knowledge in geoscience as cultural knowledge because, after all, geoscience informs engineering and engineers lead collective human efforts to rearrange water bodies and human bodies on city, region, oceanic, and planetary scales. I call this realm of inquiry geo-culture. ${ }^{9}$ Through the geo-cultural, ethnographers can join other humanities thinkers as they "lead diverse scholars and publics into uncertain environmental futures" (De Wolff and Faletti, this volume).

\section{PORT CITIES AND OCEANIC CONNECTIONS (GEO-POLITICS)}

As nodes of global trade, port cities in lower and middle latitudes have played an outsized role in organizing the fossil-fueled industrial processes that bring us to the brink of Holocene's end and have put at risk the stability of this geological epoch. Set most often in ecologically rich habitats where fresh water rivers flow into their seas, port cities also host the diverse cultural conjunctures that inspire new forms of human inventiveness, resistance, and resilience (Kane 2012). For better or worse, port cities and routes between constitute the infrastructural and architectural armature upon which, and within which, globalization processes lay their intricate and far-flung foundations, generating a suite of pervasive ideas, objects, and effects mobilized by trade. 
The historic opening of shipping routes across the Arctic follows these earlier dramatic breakthroughs in maritime engineering. These breakthroughs altered relationships between major water bodies for the efficiencies of global trade, enhancing the logistical powers of nation-states and multinational corporations. Among the monumental engineering works that heralded modernity are the canals of the nineteenth and early twentieth centuries: the opening of the Erie Canal in 1825 cut through the earth to bring ships between New York and the Great Lakes, opening up the interior of North America to trade; the opening of the Suez Canal in 1869 eliminated the need to go around Africa when, for example, sailing from India to England; and the Panama Canal in 1914 shortened routes between Europe and Asia by connecting the Atlantic and Pacific Oceans.

\section{Reorganizing Oceanic Links: The View from Winnipeg}

Engineering feats always produce winners and losers. For the city, the Panama Canal was a disaster, abruptly bringing a thirty-three-year economic boom to a crashing halt. Winnipeg had benefited from the arrival of railroad tracks linking its midcontinental location with eastern Canada in 1881, which enabled the city to become a supply depot for the rest of western Canada. With a diverse population of immigrants arriving between 1881 and 1914, Winnipeg's population grew from 9,000 to 150,000, a growth rate outpacing Chicago. But once the Panama Canal opened the cheaper sea route, it devastated Winnipeg's railway-transport business. The city became so terribly poor that it missed the urban redevelopment phase suffered by many other cities, thus leaving beautiful turn-of-the-century buildings in the Exchange District standing, to become renovated heritage architecture housing Winnipeg's thriving arts and culture scene today (figure 2.1) (Kives and Scott 2013, 38-40). And so it goes when monumental canals redesign global shipping routes by linking major water bodies in new ways: some port cities win, some lose, and some of the losses turn into unexpected boons later on. With such changes in the connections between major water bodies and accompanying forms and routes of human mobilities come pressures to change previously established hierarchies of maritime development in port cities (Kane 2012, 63-65).

Transporting this trend of infrastructure-driven change into the late twentieth century (1970s-90s), the global-scale transition to container shipping irrevocably altered shipping routes once again (Levinson 2006). This revolution grew, the story goes, from one trucker's insight that designing the hold of ships to carry stacks of containers designed to fit the size of truck beds would dramatically simplify port operations. Ports that could secure great investment no longer needed longshoremen. Redesigned docks facilitate loading containers gripped by computer-mediated cranes directly back and forth from truck beds and rail cars to ships. Thus, multimodal or intermodal freight transport was born: the technological innovation that makes Winnipeg's aspirational port possible.

Every jump in containership size and accompanying technological innovation reorganizes the dynamic flows of port city waters, ships, people, commodities, and 


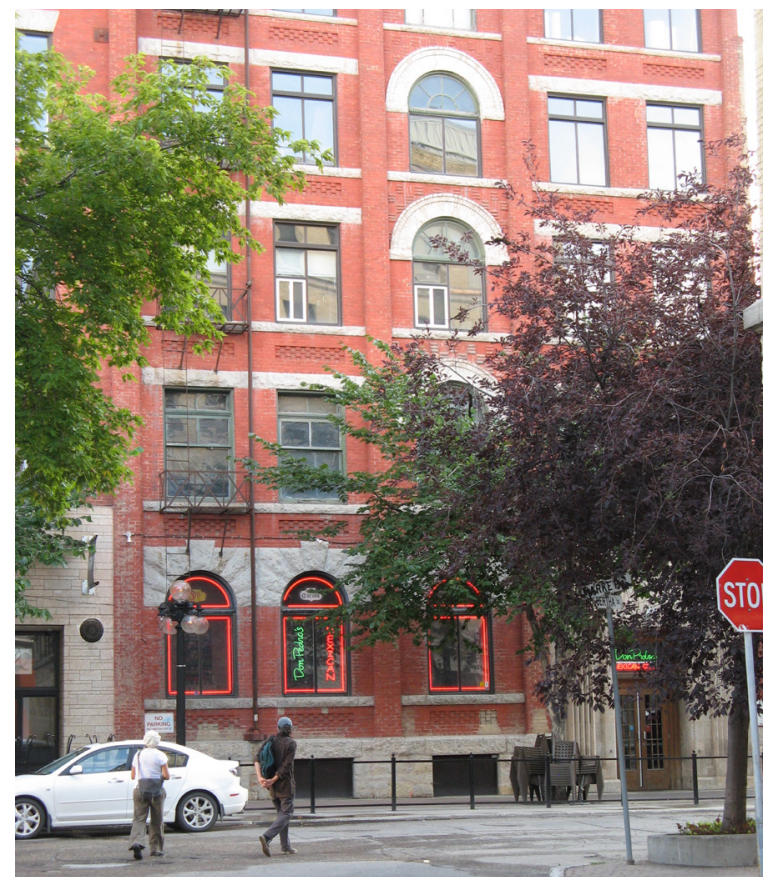

FIGURE 2.1. Contemporary renovation of heritage architecture in Winnipeg's Exchange District was made possible by the sudden diversion of global shipping through the new Panama Canal about one hundred years before. Photo by author.

information. Reorganization, however, always runs up against port city fixities (Desfor et al. 2011; Kane 2012, 118-22). From winter ice that blocks winter passage into harbors, to nineteenth-century stone and concrete docks too small for containerships, to frictions of race- and class-based inequalities that continue to order acts of dispossession and financial reward (see Tsing 2005), fixities shape dynamics of flows. So, if Winnipeg is a bellwether of future industrial fixities meeting climate change flows, port cities that link overseas producers to consumers may not even need to have their own waterfronts, whereas many coastal port cities that now enjoy thriving waterfronts may be under water.

According to the International Maritime Organization, international shipping transports more than 80 percent of global trade. ${ }^{10}$ How they move across the oceans matters: unlike the Panama and Suez canals, whose innovation was that they connected oceans and shortened shipping distances, containerization by contrast led to longer shipping distances. And while containerization was a revolution of efficiency in the transport industry, especially as it became increasingly supported by digital information technologies, it also enabled just-in-time production. Products could be assembled anywhere and everywhere. Together, the container revolution and structural manipulation of labor costs and protections triggered a global displacement of manufacturing. Manufacturing moved from Western industrialized countries, where factories closed and some major ports declined, and moved to Asia, where factories opened and ports expanded. Thus, 
containerization fundamentally restructured the nation-based political economies of the world (Mah 2014, 1-3; Cowen 2014; Mezzadra and Neilson 2019).

Exceedingly long distances between Asia and Europe or the United States and the accompanying financial and environmental costs of petroleum-based containership transport drive multinational corporate interest in Arctic Ocean routes. Like the canals of the nineteenth and early twentieth centuries, a melted Arctic offers shorter sailing distances. But unless ships sailing Arctic waters use clean energy, the reduced fossil fuel benefits of shorter distance will be offset by increases in atmospheric carbon. In and beyond the Arctic, atmospheric carbon intensifies warming temperatures. In addition to entering global air currents, wherever ships pass, their carbon pollution falls onto and darkens local ice, thereby lowering its sun-reflecting power (albedo). ${ }^{11}$

In any case, like canal construction, new passages through melting sea ice alter interoceanic flows in ways that appear to enhance efficiencies of global trade. But appearances can be deceiving. The logic of fuel efficiency ignores disruptions of hydrological patterns that may accompany melting sea ice. A melting Arctic can induce instability of cold-warm oceanic and atmospheric currents, which may shift Holocene patterns, increase the intensity and unpredictability of storms and storm surges, and hasten loss of coastal terrain and islands upon which port cities stand. Negative impacts on global trade and other forms of geopolitical chaos may attend these and other hydrological impacts of climate change.

My aim here is not to derail optimism among Winnipeg's port boosters betting on Arctic ice loss. Rather, I wish to analyze the Arctic shipping schema as a geo-cultural phenomenon driven by human intentional action directed at oceanic shipping routes and nodes. The schema fits the internationally accepted concept of oceanic space as open, empty, terra nullius. The concept is enshrined in the 1982 United Nations Convention of the Law of the Sea (UNCLOS): open waters are free for all to cross. As Steinberg (2001) has shown, however, to many of the world's peoples, even oceans have histories; for many, oceans are not empty spaces, not merely not-land.

Since nigh the beginning of the Holocene, the Arctic has been home to Indigenous peoples. How will ships plying the waters of a melting Arctic change their lives? As I learned from colleagues on the Ice Law Project, international law is Western law that occasionally entertains some exceptions for rights of Indigenous peoples and has one exception for sea ice. ${ }^{12}$ In UNCLOS, Article 234 refers to ice weaving in and under the Canadian Arctic Archipelago. But UNCLOS doesn't account for Indigenous peoples like the Inuit, whose sovereign territory is the sea. For Inuit, whether ice or water, the Arctic Ocean that flows among the islands is part of one navigable habitat for living. ${ }^{13}$

In its hardest, most durable forms, horizontal extensions of Arctic sea ice create solid terrain upon which Indigenous people dwell and navigate the cold ecologies of their subsistence and their cultures. Indigenous knowledge of sea ice reveals it 
to be an essential substance that morphs, moves, and seasonally recurs and subsides. For Inuit, ice requires nuanced interpretation to understand and survive (Krupnik et al. 2010). Indigenous knowledge shows sea ice to be fundamentally different from land in a way that confounds any simplistic relationship that Western legal instruments, like UNCLOS, posit between land and water (see Aporta 2009; Aporta, Kane, and Chircop 2018; and the Ice Law Project). ${ }^{14}$ Yet, still today, unlike Indigenous peoples who, for example, have the right to protect forests, Inuit still have no right to protect ice as an environmental good or cultural resource in international law. As Phil Steinberg put it, the problem is that "everyone has a right to break ice." 15

The fact is, except for summers, the Arctic Archipelago is still icebound, and even in summer there's enough ice around to make shipping hazardous in various ways (Arctic Council 2009; Chircop 2016, 41; Steinberg et al. 2022). If shippers from lower latitudes make no ethical or ecological distinction between functional qualities of sea ice and seawater, they may have no compunction in using icebreaking ships to force open canals. Nineteenth-century canal-building logic of transport efficiency repeats itself. Now targeting a uniquely fragile and complicated Arctic terrain, global shippers wield maritime engineering with regulations governed by a practically ice-blind legal regime.

The first suite of modern megaprojects, the Erie, Suez, and Panama Canals, were, as Ashley Carse (2014, 84-85) writes, "arguably even more symbolically charged than other transportation infrastructure like roads and railroads" precisely because the facilitation of movement "entailed the transformation of the earth itself." The symbolic charge associated with the historic human-built openings dug out to link large-scale water bodies "scrambles" uneasily with lower latitude aspirations that rely on exploiting ice-melted openings (Dodds and Nuttall 2016). In the historical trope, human engineering triumphs over nature. In the current climate-change-aware trope, however, human engineering unleashes destructive forces, some aspects of which become framed as new opportunities. This chapter tells a different story. Humans may take advantage of climate change, but they did not intend, could not have intended, to make climate change happen. In geological timespaces, only narratives that travel into spheres of unintentional agencies can make sense out of the off-kilter nature of the current existential crisis-what Amitav Ghosh (2016) calls The Great Derangement.

\section{GLACIAL ORIGINS OF HOLOCENE RIVER BASINS AND OCEAN CURRENTS (UNINTENTIONAL HISTORIES IN GEOSCIENCE TIMESPACE)}

Geologists are quite comfortable traveling in spheres of unintended agencies. Their technical knowledge can be mined as narrative resources to help tell stories of planetary pasts, presents, and futures. They study the strata of Earth's crust, seeking, 
recognizing, debating, and naming turning points in time's linear progress (Schneiderman 2015). Dramas of the most recent geological period, the Quaternary, include only the last 1.6 million years before present (b.p.) of glacial comings and goings. Within the Quaternary period, the first epoch is the Pleistocene, which starts when increasing cold envelops the planet and causes the last in a series of ice ages.

In the Pleistocene Arctic, thousands upon thousands of years of snows pile upon snows; the weight of the new falls on the old, making ice; the ice grows great lobes that push out and down across the Northern Hemisphere as glaciers. Extinctions of many large mammals and birds take place as the glacial lobes mass into the Laurentian Ice Sheet and move down into and over North America. As they move, rocks and gravel sediment stick to the glacier bottoms and carve inscriptions into the revised surfaces they push across, registering the mass movements of glacial power that will become clues for geologists.

A warming climate marks Pleistocene's end. Glaciers retreat back to the Arctic from whence they came, and rivers rush out of their bottoms as they melt. Rivers follow the glaciers' retreating path, their meltwaters gathering and swirling with a northward impulse. But they cannot flow through to join ocean currents because the glaciers that give them life block their exits. So, they converge in the center of the continent to form Lake Agassiz. Eventually, ice dams give way and Lake Agassiz bursts out of its earthen boundaries. The stages of glacial demise and their more nuanced fluxes leave patterns in once-submerged prairieland mud (which Winnipeggers call "gumbo"). About 11,70o b.p., the Pleistocene ends at the boundary of this warm period between glaciations, giving way to a new Interglacial era conducive to the development of humankind. Interglacial events inspire geologists to name a second epoch in the Quaternary something wholly new, the Holocene.

In North America, the Holocene marks the slip from life without humans to life with humans, when time immemorial and then history-as-we-know-it begins to unfold in geological timespace. In the Holocene, Indigenous peoples disperse across the continent. Many would gather seasonally at the confluence of the Red River and the Assiniboine River, in the center of a flood bowl once mostly covered by Lake Agassiz. Thousands of years would pass before Anglo-European settlers would establish the province of Manitoba as a political entity with Winnipeg, the city on the flood-prone confluence, as its capital.

If it is ever accepted by the International Commission on Stratigraphy, the already culturally secure Anthropocene concept would officially become the third epoch of the Quaternary period, marking the slip from a history that unfolds in geological timespace to a history that creates geological timespace. ${ }^{16}$ In this stratigraphic mode of reading and writing time, climate change is an anthropogenic extension and intensification of the last glacial retreat, one that will be inscribed into the planet's existing surface, one that has arisen in the sphere of unintentional agencies. Like scrapings of glacial sedimentary materials leaving evidence of their 
transport, humans intentionally etch their earthworks into the crust, also leaving a myriad of unintentional signs of passing.

At this point, I shift this continental scale story into Manitoban territory in two geological versions: a nineteenth-century tale of glacial advance and retreat and a twenty-first-century version of threshold-crossing, the four-part outburst.

A nineteenth-century Winnipeg origin story, beginning just before water's power assumes the form of great frozen lobes pushing down from the pole as the Laurentian Ice Sheet (paraphrased from Upham 1895):

Before the last ice age, braided river basins carve out a trough through the continental heart, forming a foundation for the flood bowl now inhabited by Winnipeggers. When Pleistocene glaciers mass at the North Pole, they encounter bedrock as they expand south and downward into this trough. Bedrock guides moving glaciers even as glaciers break up bedrock. Ice plows up bedrock surfaces and carries along its fragments as boulders and gravel. In the ice-rock encounter, glaciers transform bedrock's geological identity, turning solid masses into "drift." Entrained in the bottom of moving glaciers, drift writes upon new bedrock over which it scrapes, leaving scratches and marks called striae.

Bedrock turns into writing instruments and surfaces for writing upon, communicating with scientists across many millennia. Ice/waters' unintentionality meets human intentionality in the guise of geologist Upham and his assistant, Mr. Young. They travel with horse and wagon, reading the striae in the Red River valley. They travel across what had just become the Canadian province of Manitoba (although they didn't seem to be entirely aware of the colony's independence from Britain), orienting data collection in reference to the new transcontinental railroad. Interpreting changes in vanished aquatic forms of geological time, Upham writes for the new field of geology. The striae patterns provide evidence that North American glaciers move along a north-south gradient. The finding contrasts with the eastwest gradient Agassiz's European teams find, which contrast indicates how places lend diverse shapes to ice/waters' forces (paraphrased from Upham 1895, 108).

As earth warms, bringing the Pleistocene epoch to its end, glaciers degrade, forming braided rivers that, voluminously enhanced by all the melted ice, conquer the continental surface once again. But this time, as rivers move north toward Hudson Bay, they find no escape. Even in retreat, the Laurentian Ice Sheet holds its power. Resisting incoherence, the retreating ice sheet blocks the way. The ice dam captures flow from its own meltwaters. Spilling out from different portions of retreating glaciers, trapped rivers come together to form lakes. The edges of Lake Agassiz, the biggest lake, lap against the ice dam that blocks Hudson Bay. Four millennia pass with meltwaters trapped and circulating in the flood bowl's fully submerged glacial transitionary form. Meanwhile, under Lake Agassiz's bed, running straight north, a stream of water digs a shallow channel: the origin of the Red River.

Relationships and identities of the geological past persist in Winnipeg's present. Winnipeg is founded on the confluence of the Red River and the 
west-to-east-flowing Assiniboine River. Together, the two rivers organize city and surrounding farms, shaping possibilities and limits of flooding and flood control, and ultimately, the viability of Winnipeg as a port. Together, they organize all the city's infrastructure-enabled movement. Although the Red and Assiniboine Rivers have lost the central transport role they played in the time of canoes and York boats used by First Nations and first waves of settlers, the intersection of their meandering channels and flood plains creates the design of local and global transport. Roads and railroads weave around their meandering shapes, around and through neighborhoods that emanate like quilt pieces from their confluence, erroneously but traditionally called The Forks, a meeting point for inhabitants and travelers (figure 2.2).

The Demise of Lake Agassiz in Four Acts: A twenty-first-century Winnipeg origin story (from Teller, Leverington, and Mann 2002 and citations therein):

Two centuries later, still working on Manitoban events, geoscientists collectively produce a radically different kind of imaginative leap into this origin story. They utilize the most sophisticated technological advances in visualizing Quaternary events. Together with quantitative modeling techniques that extend the range and nuance of sensible measurement, geoscientists capture the glacial undoing that forcefully moves abundant freshwater from continental interior to ocean surrounds. These events, they hypothesize with confidence, probably change the course of the oceans' thermohaline currents into the very same routes that sea captains steer their ships upon today. ${ }^{17}$

By the time the ice dam blocking Hudson Bay collapsed, triggering the largest outburst in the last ice age, Lake Agassiz had merged with glacial Lake Ojibway, to form a superlake with a surface area of about 841,000 square kilometers, more than twice that of the Caspian Sea, the modern world's largest lake, and larger than modernday Hudson Bay. Lake Agassiz-Ojibway is the only lake in North America to have abruptly released huge volumes of stored water. Outbursts cut through what are now the Mississippi River Valley, St. Laurence River Valley, Mackenzie River Valley, and Hudson Strait. Following the initial outbursts, baseline flow would resume along the new routes to the ocean (see bold tentacular arrows in figure 2.3). Meltwater from these outbursts joins the oceans in a very short time period, "in critical locations and at optimal stages in the evolution of ocean circulation." Combined with longer-term fluxes of Lake Agassiz, the outbursts "probably played an integral role in global ocean and climate history during the last deglaciation," pushing the system over a threshold. (paraphrased from Teller, Leverington, and Mann 2002, 883-85)

Teller, Leverington, and Mann theorize that any one of four episodes in which large volumes of lake water suddenly burst out of the confining but collapsing walls of the Laurentide Ice Sheet may have altered circulation patterns of ocean currents and triggered a series of widespread climate changes. Ice/water's logistical power at continental scale breaks into planetary scale when it pushes the earth's 


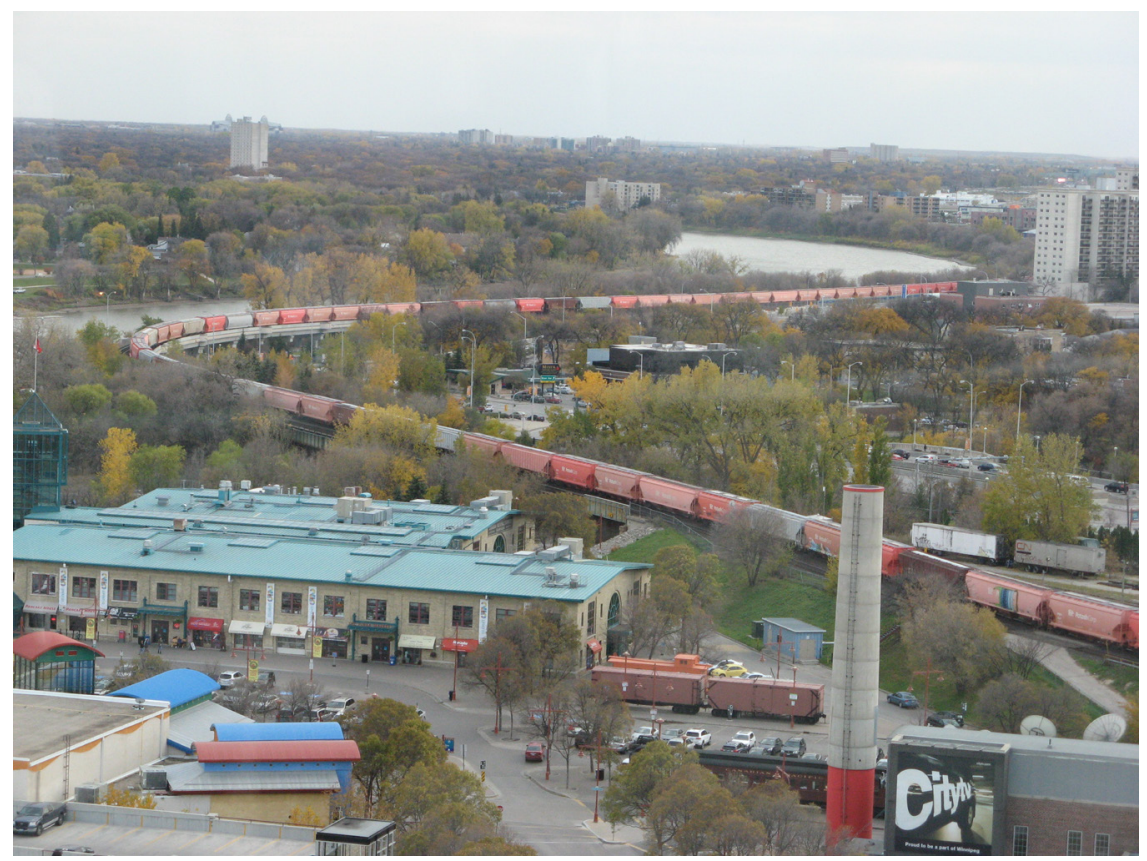

FIGURE 2.2. Red River and railcars moving toward the Forks. View from Canadian Museum of Human Rights. Photo by author.

system over a threshold. Crossing that threshold catapults relations between freshwater circulating in glaciers and rivers and saltwater in oceans into the Holocene configuration that humans find when they arrive in North America. In the mapimage (figure 2.3(A)), Winnipeg, though unmarked, is centrally located near what was once Lake Agassiz-Ojibway, well within the source terrain from which the global impulse projects itself toward the oceans.

The authors' quantitative model and accompanying narrative briefly sketched here characterizes unfolding events in geological timespace. This diachronous representation contrasts with their map-image, which collapses into a unified and flattened form the hypothetical events that unfold over several millennia. As a cultural artifact, the map-image effectively projects the viewers' mind into the condensed past of deep time. In addition to condensing time, the map-image contains a cartographic sleight of hand: the ghostly map lines of sovereign nation-states penned lightly into the background insert a geo-politics that is, in fact, not even a glint in the planet's eye.

If the planet crosses over yet another threshold in this century, we shall catapult out of the Holocene and into the unknown. What humans do now with scientific knowledge will-in the best of scenarios-allow the planet to stabilize in a 
new, gradually warming interglacial state. In the worst scenario, it could force the nightmare trajectory toward a "Hothouse Earth" (Steffen et al. 2018, 8253, their figure 1), destabilizing life on the planet.

On the wings of the Anthropocene concept, geoscience pushes out of expert spaces and into broader cultural ones. Human collectives are coming to understand the significance of events taking place in geological spheres of unintended human and aquatic agencies. With nuanced attention to human-ice/water relations, humanities scholarship can craft ethical and political questions, experiments, and stories to help navigate unfolding planetary processes. Here follows one last retelling, this one integrating deep past, present, and future timespaces.

\section{ICE/WATERS' AGENCIES AND WINNIPEG'S ANTICIPATORY PORT (PATH DEPENDENCIES)}

\section{Steel Routes of Transnational Capitalism}

For better or worse, CentrePort investment speaks to the adaptability of infrastructural logistics. Old pathway dependencies may fade as a melting Arctic lures global trade to the top of the world. ${ }^{18}$ The plans of Winnipeg's port boosters, if successful, would confound a basic assumption about port cities. Throughout most of human history, port cities have drawn logistical power from their spatial location in strategic coastal and/or riverine edges. In these geographic situations, they are poised to link water routes and land markets. However, if the future unfolds as the global shipping industry and Canadian maritime government officials anticipate, CentrePort would become an "Arctic Bridge" between Canada and Russia, and between Atlantic and Pacific Oceans (Arctic Council 2009, 11-12). Setting at the northernmost end of the once "NAFTA Highway" (since 2018, the "Mid-Continent Trade Corridor"), cargo would move through CentrePort to and from Russian and Asian markets by three Class I railways, ${ }^{19}$ a $24 / 7$ global air cargo airport, and an international trucking hub (see cities along railroad tracks in figure 2.3).$^{20}$

Conventional geovisualizations of port cities rely on images of ships crossing oceans heading back and forth between preset latitude-longitude points along the edges of continental or island land masses. For ports that don't yet have conditions to thrive, that is, for spatialized investment regimes that anticipate profits from future conditions, this visual convention must be reimagined. CentrePort boasts twenty thousand acres on the city's outskirts ready to host port-related investment. Geovisualizations supplement this landlocked footprint with multimodal infrastructural extensions (ship, train, truck networks). These intensify use of existing path dependencies (e.g., railroad lines linking the Red River basin to those in the Mississippi River basin) by exploiting the possibility of future path dependencies across the Arctic Circle. In this way, the Gateways Map illustrates the logistical power of port cities to concentrate and interconnect anticipated nodes of multimodal transport activity dependent on ice-free Arctic passage. 


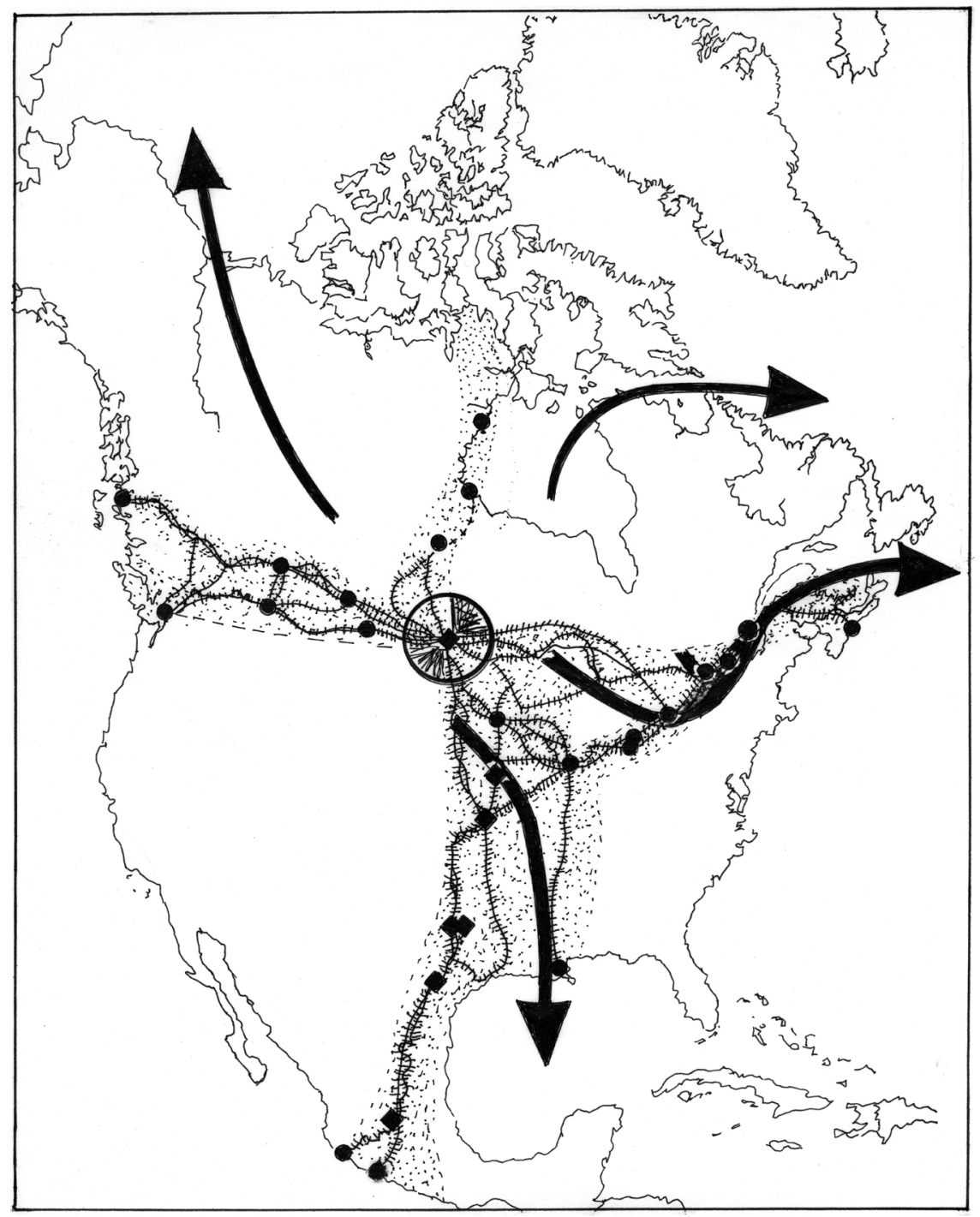

FIgURE 2.3. The Double Artifact: A) geoscience and B) port city projection. A) The four bold tentacles represent the Lake Agassiz outburst (geovisual data from Teller, Leverington and Mann 2002: 880). B) CentrePort's Gateways map of railroads (hatched lines) and cities (circles and squares), Winnipeg in center circle. The singular artifacts overlie NAFTA's ghostly cartography. Original composite drawing by author, from book manuscript (in prep) "Geo-culture: The Ethnography of River-City Flood Control." Composite image by author.

The Gateways' graphic is a cartographic image; an industrial, maritime artifact made to impress potential investors. It projects the viewer's mind into a potential future when CentrePort routinely brings places like Murmansk, Russia, in the 
Arctic Circle, together with New Orleans through Churchill, the Hudson Bay port, and Winnipeg, creating new commodity connections among the world's biggest markets. Note that the image-map space between Winnipeg and Churchill, absent a railroad line, remains sketchy. Nevertheless, the website's optimistic text elaborates on developing connections among new and older transport infrastructures. The logistics of future success rely on a graphic assumption that shipping will shift northward as twenty-first-century climate change occurs.

\section{Back to the Spheres of Unintended Agencies: A Visual Experiment}

In North America, the logistical power of fresh water derives from ice. This is the lesson I learn from the glacially inspired imagination of Teller, Leverington, and Mann's outburst model. The struggle for power between glaciers and meltwaters and the eventual stabilization of ice/water interfaces and ocean currents are significant geological events. Together, liquid and solid, fresh and salt waters contributed to moving the planet across the epochal boundary between Pleistocene and Holocene. When glacial lobes of the Laurentide Ice Sheet pull back to the pole, they free meltwaters coming from their own bodies. Yet its meltwaters circulate, still, in the very patterns born of the ice sheet's partial defeat. The port city nodal organization of railroad, road, ship, and air lines of twenty-first-century transport grows directly into and around the seasonally recursive versions of these flows and impasses.

I discovered the degree to which the linear forces of human transport correspond to those created by the outbursts from Lake Agassiz quite unintentionally. The discovery emerged as part of my larger geo-cultural experiment. Working my way through various archival pathways, I came upon a telling visual coincidence that illuminates how geological spheres of unintended agencies govern CentrePort aspirations.

The graphic coincidence appearing in my data juxtaposes two timescapes (see Adam 1998). Each is situated in a different layer and portion of geological time. Looking into the past, the outburst map presents a current scientific model of North American flows at Pleistocene's end. The graphic collapses several millennia of ice/water history in which the topography of the continental crust and pathways of the ocean currents come to assume the forms and positions familiar today, whereas, looking into the future, CentrePort's Gateway map presents a portion of the current industrial global transport imaginary that feeds on an open Arctic. The CentrePort graphic collapses timescapes between the nineteenth- and twenty-first-century investment horizons, including those in which humans construct nation-state territories and build the interconnecting railroads, as well as Winnipeg's current investor dream of becoming a global port.

One looks to the past, one looks to the future, but both occupy the same space. I study the two heretofore unrelated artifacts: each depicts a global impulse that connects the geographic center of North America with three oceans (Gulf of Mexico, Arctic, and North Atlantic). In each, the global impulse is rendered in the 
form of powerful and expansive tentacles projecting outward from Winnipeg and its environs.

The coincidence emerges because of my ethnographic impulse to experiment with different kinds of ice/water knowledge, juxtaposing ideas and things that don't usually belong together. And the coincidence extends beyond the intertwining outburst-rivers and railroads. In both artifacts, I can see faint outlines of sovereign territories that situate the emerging tentacles. ${ }^{21}$ Drawn with the thinnest of pens, the continental and island coastlines, the divisions between countries (and in one, states and provinces) appear clear yet ghostly beneath the dramas of spectacular global expansion. The repetition of framing is odd given that happenstance brings about the artifacts' relationship: the artist-cartographers use almost the exact same base map. So similar are they, that with a little adjustment of scale on the photocopier, I easily combine the images into one without distorting the content or frame of either. The experiment inspires a visual analysis of intertwining and emanating flows of water, steel, and knowledge.

There is something significant in the trick of global scale that renders space inhuman in the doubled artifact from geoscience and trade. The significant something arises from a humanities perspective on ice/water. In both, the sleight-of-hand plane formed by the pale outlines of sovereign territories set off a viewer's sense of sheer magnitude and irrepressible directionality of the tentacles projecting across abstract land-ice-sea space. The renderings of global impulses need the barest reference to the world we know so that viewers can orient and sense proportion. A vague but familiar geopolitical map underpins a theory of geoscientists and the anticipation of global shippers. The maneuver enables the artifacts as effective visual technologies, essentially making distant past and future seem plausible.

Together, map-images in the double artifact hold the codes of an empirically grounded imaginary that stretches from ice age deep time to transnational capitalist futures. I realize that by combining them, I read things into them that their creators do not intend. For me, the coincidence in the visual rendering of global impulses provides sufficient justification for this ethnographic experiment that takes seriously the spheres of unintended agencies. An industrial dreamland enabled by empirically grounded yet hypothetical geoscientific ghost-outbursts offers a dynamic for unpacking human-water relationships across environmental scales. The double artifact sidesteps the often-tedious boxes of ecological habitats with stakeholders nested neatly in watersheds, nations, regions, and policies. And like the Arctic itself, it opens pivotal geological timespaces to cultural exploration.

\section{CONCLUSION: ICE ENLIGHTENMENT}

Our ability to create conditions that may knock the planet out of the Holocene, the epoch that has been so kind to the development of our species and our more-than-human cohabitants, has been discovered only after the fact, or at least, 
after much harm has been done. This ability to do great harm was unintentional. So even as we must hope for, energize, and rely upon the good and smart intentions of humans to act upon the knowledge signaled by the geo-cultural communiqué of the Anthropocene, we cannot be so arrogant as to assume that the ability of humans to intend is sufficient. Even with ever-advancing technology, the reach, and certainly the nuance, of the sparking but ever so brief presence of human intentionality is no match for the complex scope of planetary life processes. We have to make an ally of ice, understanding its shape-shifting formations and qualities and, most importantly, working with ice's logistical powers of stabilization.

This idea returns to Chandra Mukerji's (2009 and this volume) insight that water lends its agency to people in the form of logistical power. To get water to flow through the Canal du Midi from Mediterranean to Atlantic, engineers, surveyors, and local peasants with skills inherited from the Romans had to change relations among rocks, soils, sands, mountains, and a monarchy. In the exchange of agency, water changed relations well beyond their intentions. In seventeenthcentury France, nineteenth-century Erie in New York, Suez in Egypt, or earlytwentieth-century Panama, if engineered correctly, water flows, connecting oceans in unnatural ways and changing destinies of port cities and nation-states. And in the twenty-first-century Arctic, as ice diminishes with warming temperatures, water flows into channels cracked open by ice-breaking ships in the Canadian Archipelago and Siberia. In a process of what Mukerji might call "impersonal rule" although involving multinationals rather than monarchies, ice-breaking ships are apt to destroy or confuse time-honored trails of Indigenous hunters and animals. ${ }^{22}$ Old and new, trails, canals, and channels crisscross the earth, material evidence that human collectivities, like glacial lobes, inscribe movement, stasis, struggle, and art into the always revising surface of Earth (figure 2.4).

The spatial coincidence that emerged from combining geoscience and port industry geovisualizations shows that if the well-frozen Arctic to its north disappears, Winnipeg might bear the fruits of a multimodal system that links Siberia to the Gulf of Mexico. Drawing on the logistical power of ice/water, the city is planning to extend land and air tentacles into some of the new-Holocene paths carved out by Lake Agassiz-Ojibway's original outbursts. Indeed, if CentrePort boosters are right, the city's near-term future might shine as brightly as it did in its Golden Age when railroads first came through town. But it would shine quite briefly, I fear. In the longer term, crossing the next climate threshold (a possible event hastened by a melting Arctic) would not be survivable. There is no coming back from the bust that would almost surely follow this boom. Is there a way to hold such promise and threat together in one's mind? Might it be possible for Winnipeggers and global shippers more generally to borrow meltwaters' logistical power without hastening a more dangerous future?

Such questions can be put to work. Humanities scholars experimenting with ways of knowing and being can wield revelatory coincidence, loosening the 


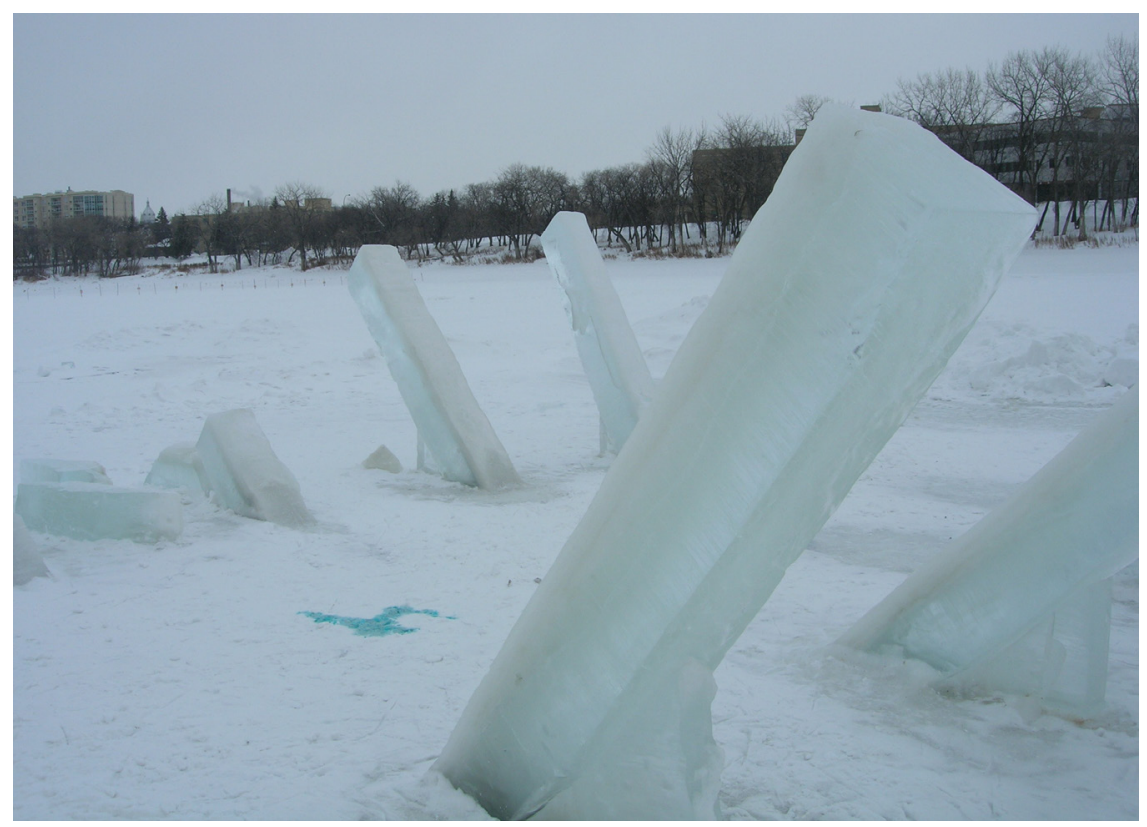

FIGURE 2.4. Ice Sculpture. When the air is cold enough and the ice is deep enough, artists sculpt the Red River at the Forks. February 10, 2007. Photo permission granted by Beverly Peters, Winnipeg.

fixities of our intentions to clarify the diversity of our options. By "staying with the trouble," as Donna Haraway (2016) suggests, this chapter writes a city into glacial timespace, joining others in a call to protect the ice/waters that move us.

\section{ACKNOWLEDGMENTS}

The material presented here draws from a book-in-progress provisionally entitled "Geo-Culture: The Ethnography of River-City Flood Control." I received support for the 2014 field research as Resident Chair in Environmental Science at University of Winnipeg's Richardson College for the Environment and Science, from the Council for International Exchange of Scholars (CIES), Fulbright Canada, and the College of Arts and Sciences and Vice Provost for Research at Indiana University. I presented an earlier version at the annual meeting of the American Anthropological Association in Washington, DC, on December 2, 2017. More generally, the ideas have been inspired by ongoing conversations about Arctic ice and global shipping with Claudio Aporta, Aldo Chircop, Kate Coddington, and Phil Steinberg and by participation in the ICE LAW Project, supported by the Leverhulme Trust (Grant IN-2015-033). I thank the volume's editors for their queries and comments along the way. 


\section{REFERENCES}

Adam, Barbara. 1998. Timescapes of Modernity: The Environment and Invisible Hazards.

New York: Routledge.

Arctic Council. 2009. Arctic Marine Shipping Assessment 2009 Report. https://oaarchive .arctic-council.org/handle/11374/54, accessed December 10, 2018.

Aporta, Claudio. 2009. "The Trail as Home: Inuit and Their Pan-Arctic Network of Routes." Human Ecology 37 (2): 131-46.

Aporta, Claudio, Stephanie C. Kane, and Aldo Chircop. "Shipping Corridors through the Inuit Homeland.” Limn \#10. https://limn.it/articles/shipping-corridors-through-the-inuit -homeland/.

Carse, Ashley. 2014. Beyond the Big Ditch: Politics, Ecology, and Infrastructure at the Panama Canal. Cambridge, MA: MIT Press.

Carter, Natalie, Jackie Dawson, Jenna Joyce, and Annika Ogilivie. 2017. Arctic Corridors and Northern Voices: Governing Marine Transportation in the Canadian Arctic. Environment, Society and Policy Group, University of Ottawa. www.espg.ca.

Chakrabarty, Dipesh. 2009. “The Climate of History: Four Theses.” Critical Inquiry 35 (2): 197-222.

Chircop, Aldo. 2016. "Sustainable Arctic Shipping: Are Current International Rules for Polar Shipping Sufficient?" Journal of Ocean Technology 11 (3): 39-51.

Cowen, Deborah. 2014. The Deadly Life of Logistics Mapping: Violence in Global Trade. Minneapolis: University of Minnesota Press.

Desfor, Gene, Jennefer Laidley, Quentin Stevens, and Dirk Schubert, eds. 2011. Transforming Urban Waterfronts: Fixity and Flow. New York: Routledge.

Dodds, Klaus, and Mark Nuttall. 2016. The Scramble for the Poles. Malden, MA: Polity.

Ghosh, Amitav. 2016. The Great Derangement: Climate Change and the Unthinkable. Chicago: University of Chicago Press.

Hansen, Bert. 1970. "The Early History of Glacial Theory in British Geology." Journal of Glaciology 9 (55): 135-41.

Haraway, Donna. Staying with the Trouble: Making Kin in the Chthulucene. Durham, NC: Duke University Press.

Irmscher, Cristopher. 2013. Louis Agassiz. Boston: Houghton Mifflin Harcourt.

Kane, Stephanie C. 2012. Where Rivers Meet the Sea: The Political Ecology of Water. Philadelphia: Temple University Press.

- 2018. "Where Sheets of Water Intersect: Infrastructural Logistics and Sensibilities in Winnipeg, Manitoba.” In Territory beyond Terra, edited by Kimberley Peters, Philip Steinberg, and Elaine Stratford, 107-26. London: Rowman and Littlefield.

Kelly, Jason M., Philip Scarpino, Helen Berry, James Syvitski, and Michel Meybeck, eds. 2018. Rivers of the Anthropocene. Oakland: University of California Press.

Kives, Bartley, and Bryan Scott. 2013. Stuck in the Middle: Dissenting Views of Winnipeg. Winnipeg: Great Plains Publications.

Krupnik, Igor, Claudio Aporta, Shari Gearheard, Gita J. Laidler, and Lene Kielsen Holm. 2010. Siku: Knowing Our Ice; Documenting Inuit Sea-Ice Knowledge and Use. New York: Springer.

Levinson, Marc. 2006. The Box: How the Shipping Container Made the World Smaller and the World Economy Bigger. Princeton NJ: Princeton. 
Linton, Jamie. 2010. What Is Water? The History of an Abstraction. Vancouver: UBC Press. Mah, Alice. 2014. Port Cities and Global Legacies: Urban Identity, Waterfront Work, and Radicalism. New York: Palgrave Macmillan.

Mezzadra, Sandro, and Brett Neilson. 2019. The Politics of Operations: Excavating Contemporary Capitalism. Durham, NC: Duke University Press.

Mukerji, Chandra. 2009. Impossible Engineering: Technology and Territoriality on the Canal du Midi. Princeton: Princeton University Press.

Raffles, Hugh. 2002. In Amazonia: A Natural History. Princeton: Princeton University Press. Schmidt, Jeremy. 2017. Water: Abundance, Scarcity, and Security in the Age of Humanity. New York: NYU Press.

Schneiderman, Jill S. 2015. "Naming the Anthropocene." philoSOPHIA 5 (2): 179-201.

Sideris, Lisa. 2016. "Anthropocene Convergences: A Report from the Field." In Whose Anthropocene? Revisiting Dipesh Chakrabarty's "Four Theses," edited by Robert Emmett and Thomas Lekan. Transformations in Environment and Society 2: 89-96.

Somerville, Margaret. 2013. Water in a Dry Land: Place-Learning through Art and Story. New York: Routledge.

Steffen, Will, John Rockström, Katherine Richardson, Timothy M. Lenton, Carl Folke, Diana Liverman, Colin P. Summerhayes, et al. 2018. "Trajectories of the Earth System in the Anthropocene." Proceedings of the Academy of National Sciences (PNAS) 115 (33): 8252-59.

Steinberg, Philip E. 2001. The Social Construction of the Ocean. Cambridge: Cambridge University Press.

Steinberg, Philip, Greta Ferloni, Claudio Aporta, Gavin Bridge, Aldo Chircop, Kate Coddington, Stuart Elden, Stephanie C. Kane, et al. 2022 (forthcoming). "Navigating the Structural Coherence of Sea Ice" (working title). In Unsettling Ocean Legalities, edited by Irus Braverman. Oxfordshire: Routledge.

Strang, Veronica. 2004. The Meaning of Water. Oxford: Berg.

Subramanian, Meera. 2019. "Anthropocene Now: Influential Panel Votes to Recognize Earth's New Epoch.” Nature. May 21, 2019. www.nature.com/articles/d41586-019-01641-5.

Syvitski, Jaia, Colin N. Waters, John Day, John D. Milliman, Colin Summerhayes, Will Steffen, Jan Zalasiewicz, et al. 2020. "Extraordinary Human Energy Consumptions and Resultant Geological Impacts Beginning Around 1950 CE Initiated the Proposed Anthropocene Epoch." Communications Earth and Environment 1(32): 1-13.

Teller, James T., David W. Leverington, and Jason D. Mann. 2002. "Freshwater Outbursts to the Oceans from Glacial Lake Agassiz and Their Role in Climate Change during the Last Deglaciation." Quaternary Science Review 21: 879-87.

Tsing, Anna Lowenhaupt. 2005. Friction: An Ethnography of Global Connection. Princeton: Princeton University Press.

Upham, Warren. 1895. The Glacial Lake Agassiz. Washington, DC: U.S. Geological Survey.

Whyte, Kyle P. 2018. "Indigenous Science (Fiction) for the Anthropocene: Ancestral Dystopias and Fantasies of Climate Change Crises." Environment and Planning E: Nature and Space. 1 (1-2): 224-42.

Williams, Mark, Jan Zalasiewicz, Neil Davies, Ilaria Mazzini, Jean-Philippe Goiran, and Stephanie Kane. 2015. "Humans as the Third Evolutionary Stage of Biosphere Engineering of Rivers." Anthropocene 7: 57-63. 
Yusoff, Kathryn. 2016. "Anthropogenesis: Origins and Endings in Anthropocene." Theory, Culture, \& Society 33 (2): 3-28.

\section{NOTES}

1. This chapter is part of a larger ethnographic field-based book project on flood control in Winnipeg Canada. My working title is "Geo-Culture: The Ethnography of River-City Flood Control." Figure 2 comes from the manuscript (under review).

2. For a recent statement on the question of onset and official geological status of the Anthropocene, when human action triggered climate change and its widespread effects, see Subramanian (2019) and Syvitsky et al. (2020).

3. Ethnographers also tend to import the basic hydrological assumption that water is composed of $\mathrm{H}_{2} \mathrm{O}$ molecules. Not an unreasonable assumption perhaps. As they gather and flow, cycle, and change state with temperature, gravity, and wind, $\mathrm{H}_{2} \mathrm{O}$ molecules implicitly provide elemental material for cultural meaning. When oceans and rivers become performance stages for human action (e.g., ships plying the sea) or habitats for human and more-than-human relationships (e.g., petrochemical and plastic pollution), their molecular composition as $\mathrm{H}_{2} \mathrm{O}$ (plus dissolved compounds) is taken for granted. But it is also possible that water's atomic character somehow conceals embodied senses of water's agency. The extent to which water's molecular nature governs meaning in hydrological science is the subject of Jamie Linton's (2010) "history of a modern abstraction." He analyzes the conceptual limitations of water stripped of its environmental, social, and cultural contexts. And also, when the idea of water/ $\mathrm{H}_{2} \mathrm{O}$ turns into a "total geological fact," as Jeremy Schmidt $(2017,4,14,208)$ finds in his intellectual history, the water's meaning is reduced to its stature as an absolutely necessary resource. In turn, water managers promote themselves as practitioners who make social life possible and as key agents of modern planetary progress.

4. The ethnography of water is extensive; for a range of approaches see, for example, Raffles (2002), Strang (2004), Kane (2012), and Somerville (2013).

5. I use a definition of agency inherited from seventeenth-century English: "Ability or capacity to act or exert power; active working or operation; action, activity." Oxford English Dictionary (2:4).

6. This outward exploration of unintentional spheres reverses the inward orientation of psychoanalysis.

7. With Jaia Syvitski and Kimberly Rogers of CSDMS, University of Colorado, I have been exploring meso-scale spaces of water infrastructure in a project titled "Humanizing Remotely Sensed Visions of the Earth: River Infrastructure in Image, Ethnohistory and Geohydrology."

8. I learned about CentrePort when I went to interview its vice president for planning and development in its downtown office to discuss flood control (the focus of my larger ethnographic project). Interview with John Spacek, November 21, 2014, field notes book no. 4, 64-75.

9. I first developed the concept of infrastructural culture to capture the broad cultural significance of flood control engineering practices in Winnipeg (Kane 2018). I then broadened the concept and renamed it as geo-culture to refer to the way urban inhabitants embed themselves in the crust of the earth and, not so unlike the glaciers of the last ice age, reshape it. By approaching human action through an ethnography of cities and their situated intra-actions with ice/water bodies, I sidestep much of the "homogeneous geomorphizing of the Anthropocene" (Yusoff 2015, 3) that accompanies critical debates of species-level analysis (e.g., Chakrabarty 2009; Sideris 2016; Whyte 2018).

10. The IMO is the United Nations agency responsible for the safety and security of world shipping and for protecting the seas and atmosphere from ship pollution. www.imo.org/en/About/Pages /Default.aspx, accessed December 10, 2018. Note too that between 2015 and 2017, shipping traffic has increased 75 percent, mostly in Nunavut Province, homeland of the Inuit and directly north of Winnipeg's provincial home of Manitoba (Carter et al. 2017, 4). 
11. www.npolar.no/en/facts/albedo-effect.html, accessed December 10, 2018.

12. For more on the interdisciplinary research network called the Ice Law Project, convened by the Centre for Borders Research at Durham University, 2014-19, see https://icelawproject.org/.

13. See, for example, Aporta (2009); Aporta, Kane, and Chircop (2018).

14. The Ice Law Project (ILP) investigated the potential for an ice-sensitive legal framework for governing potentially conflicting activities such as global shipping and Indigenous livelihoods in the frozen Arctic Ocean. The ILP archive is available at: https://icelawproject.weebly.com/.

15. Phil Steinberg clarified Chircop's argument for me in an email, February 16, 2019. Aldo Chircop raised the legal problem in a coleader discussion of the Ice Law Project in Stockholm with Phil Steinberg, Stuart Elden, and me on June 21, 2017. See also Steinberg et al. (2022, forthcoming).

16. For rivers as key actors in the scholarly materialization of the Anthropocene, see Williams et al. (2015) and Kelly et al. (2018).

17. National Ocean Service, Currents: "Thermohaline Circulation." https://oceanservice.noaa.gov /education/tutorial_currents/o5conveyor1.html, accessed November 20, 2018.

18. See also: www.centreportcanada.ca.

19. Canadian National, Canadian Pacific, and BNSF Railways.

20. See note 18.

21. The geoscience article also shows latitude ( 30 and 60 degrees) and longitude ( 30 to 150 degrees). Both geoscience and trade images extend partway into the Arctic and partway into Mexico.

22. See, for example, www.ntkp.ca/ and www.anijaarniq.com/. 